\title{
Application of Analytical Hierarchy Process (AHP) for Assessment of Collection and Transportation of Solid Waste: An Empirical Study
}

\author{
Gnanasekaran Sasikumar*†, A. Sivasangari** and N.Venkatachalam*** \\ *Department of Mechanical Engineering, GMR Institute of Technology, Srikakulam-532 127, Andhra Pradesh, India \\ ***Department of Electronics and Communication Engineering, GMR Institute of Technology, Srikakulam-532 127, \\ Andhra Pradesh, India \\ **Department of Mechanical Engineering, Excel Engineering College, Komarapalayam-637303, Tamilnadu, India. \\ $\dagger$ Corresponding author: Gnanasekaran Sasikumar; sasikumar.g@ gmrit.edu.in
}

Nat. Env. \& Poll. Tech.

Website: www.neptjournal.com

Received: 08-06-2021

Revised: $06-07-2021$

Accepted: 13-07-2021

\section{Key Words:}

Urban local bodies

Analytical hierarchy process

Solid waste management

Consistency ratio

\begin{abstract}
Cities and Urban Local Bodies (CULB) are considered to be the engines of economic growth and any significant improvement in their operational efficiency will lead to a positive impact on the economy. The major portion of expenditure on Solid waste management (SWM) of CULBs is spent on waste collection and transportation activities. To enhance the efficiency of SWM, it is essential to collect and transport solid waste in a scientific manner. As a result, systematic solid waste collection and transportation will effectively resolve and improve SWM concerns. In this paper, Analytical Hierarchy Process (AHP) method is adopted to appraise various alternatives of solid waste collection and transportation methods of municipal solid waste in Visakhapatnam city, India. The additive normalization method is applied for calculating the criteria weights. The fairness of judgment is checked by the consistency ratio. To calculate AHP accurately and fast, a decision support system was built. The findings of the study will be beneficial in evaluating existing solid waste collection and transportation processes to improve the operational efficiency of managing SWM.
\end{abstract}

\section{INTRODUCTION}

Waste is generated from various sources such as households, markets, industries, hotels and restaurants, institutions, and other organizations. Waste can exist in solid, liquid, and air forms. According to India's 2011 census, urban India contributed 63 per cent of the country's GDP, with that figure expected to rise to over 75 per cent by 2030 . The country's strong GDP development is being hampered by the waste crisis, with waste generation expected to reach 165 million tonnes by 2030. The challenges of proper collection and transportation play a vital role in making our cities clean and smarter. Apart from the quantity of waste generated, proper waste collection, sorting, and transportation must be carried out in a methodical manner. The existing collection, waste separation, and transportation CULBs techniques are not designed to handle solid wastes efficiently. As a result, in order to meet the public's requests and clean up the city, a resilient, robust, scientific, and people-centric SWM method is required. Such scientific SWM procedures will allow for more efficient resource management and improved usage. Solid waste management is a difficult operation that necessitates a lot of attention from the public and the institutions involved (Chouhan \& Reddy 1996, Mazumdar 1994).

\section{PAST STUDIES}

Poor practices of solid waste management will lead to major financial, environmental pollution, and health problems to society (Hazra et al. 2017). Due to the decentralization of funds, the evaluation of municipal budgets requires a lot of attention. The municipal budgets of five significant Indian cities were analyzed to see how much money could be spent on SWM (Sekhar \& Bidarkar 1999). Multi-Criteria Decision Making (MCDM) techniques such as the Simple additive weighting method and TOPSIS were applied to study and relate the SWM methods (Jovanovic et al. 2016). The selection of suitable solid waste collection systems with a major focus on improving waste recovery rate was dealt and the use of environmental impact data was reported (Ulukan \& Kop 2009). A combined model based on the weighted linear combination method and AHP is applied for evaluating the fitness of the landfill site for MSW (Mazaher Moeinaddini 2010). A novel Stratified Best-Worst method was implemented for identifying a suitable waste disposal technology selection in Iran (Torkayesh et al. 2021).

Geographical Information System and TOPSIS technique were used to identify alternative solid waste landfill sites among six areas in Turkey (Yildirim et al. 2018). A 
review of MCDM applications in Municipal SWM including methodology, type of wastes, priority methods, calculation of consistency ratio was discussed elaborately (Goulart Coelho LM et al. 2017). An MCDM model was developed using ELECTRE III to identify the best location for waste treatment plants to handle e-wastes in Greece (Ch. Achillas et al. 2010).

Based on the literature review, it is found that evaluation of solid waste collection and transportation method falls that under MCDM includes the following issues:

- Conflicting criteria and their objectives with respect to the problem

- Nature of criteria and sub-criteria

- Alternatives with different merits and demerits

Hence, the above issues are solved using the AHP method as it is considered to be the best method to address the above problems.

\section{EXISTING PRACTICES OF SOLID WASTE MANAGEMENT IN VISAKHAPATNAM}

Visakhapatnam is positioned in the northeastern part of the state of Andhra Pradesh, India which has a population of $2,175,000$ as of 2020 . The city is located $170-15$ ' and $180-$ 32 ' in the north latitude and 180-54 and 830-30 'east latitude. Many reputable industrial settings are located in and around Visakhapatnam, resulting in a higher volume of waste generation. The city is managed by the Greater Visakhapatnam Municipal Corporation (GVMC).

\section{Collection and Transportation of Waste in GVMC}

The collection, transportation, and disposal of solid waste are carried out by the Public Health Department of GVMC. The GVMC follows 3 levels of waste collection systems such as (Kameswar Rao 2019):

i. Door-to-door waste collection (primary collection system): The separated waste at the domestic level is collected and conveyed by Push Carts and Tri-Cycle to transfer centers.

ii. Waste collection from households by dumper and RCC bins (secondary collection).

iii. Shipping of waste to landfill sites (third level).

The main compositions of solid waste produced in Visakhapatnam are organic waste. The city generates 1100 MT of waste per day out of which domestic waste accounts for 450 tons.day-1 and commercial, drain silt, and others will be 550-600 tons.day-1.

Solid trash collection and transportation take place in two shifts. During the first shift, workers collect and transfer waste to open collection stations using six container wheelbarrows, push cars, or tricycles. This waste is transported to transfer facilities using dumper placers, tippers, and tractors. The waste from the transfer station is then collected and transported to the disposal site by 20 tonners and open trucks.

\section{ANALYTIC HIERARCHY PROCESS MODEL DEVELOPMENT}

The AHP is one of the Multiple Criteria Decision Making (MCDM) techniques for evaluating alternatives which was introduced by Saaty (1980). In AHP, quantitative and qualitative performances of alternatives are evaluated through a simple hierarchy structure and application of numerical scale (Lee et al. 2001). This AHP model involves subsequent steps:

Step 1: Identifying the criteria for the MCDM problem

Step 2: Constructing decision structure by dividing the problem into different levels consisting of criteria and alternatives

Step 3: Developing pairwise comparison matrix ' $A$ ' using equation 1:

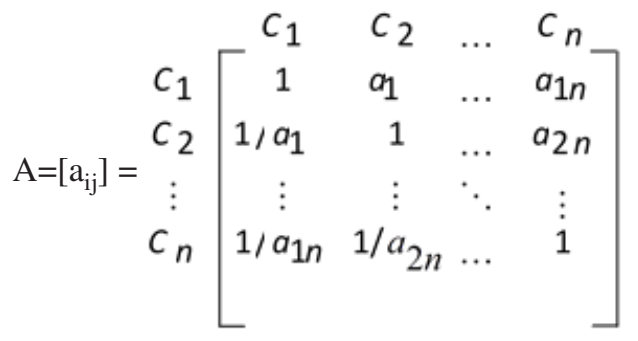

where $a_{i j}=1$ and $a_{j i}=1 / a_{i j}, i, j=1,2, \cdots, n$

$C_{1}, 2, \ldots, C_{n}$ signifies criteria involved in the problem, while $\mathrm{a}_{i j}$ shows decision on criteria $C_{i} C_{j}$.

The comparative importance of two elements is valued by $1,3,5,7$, and 9 , where 1 means "equally important", 3 indicates "slightly more important", 5 shows "significantly more important", 7 signifies "strongly more important", and 9 means "extremely more important" (Saaty 2000).

Step 4: By normalizing the column, adding each row element, and dividing the total by the number of elements in the row, the weight of the pairwise comparison matrix may be calculated.

Step 5: Checking the consistency of each comparison matrix to ascertain the consistency of expert judgment by computing the consistency index $(\mathrm{CI})$ and consistency ratio (CR) by equations $2 \& 3$ :

$$
C I=\frac{(\lambda \max -n)}{(n-1)}
$$




$$
C R=C I / R I
$$

where $n$ and $\lambda_{\max }$ denotes the size of matrix and Eigenvalue. The judgment consistency is tested by CR which is obtained by dividing $C I$ with Random index (RI) from Table 1 . The $C R$ is satisfactory if it is below 0.10 (Saaty 1980).

\section{APPLICATION OF ANALYTIC HIERARCHY PROCESS MODEL FOR SOLID WASTE MANAGEMENT}

The AHP method is used for assessing the SWM practices particularly for solid waste collection and transportation at GVMC and the following steps are involved in the case study:

\section{Defining Qualitative and Quantitative Criteria}

Constructing a hierarchy structure for AHP based SWM with 4 main criteria (Technical, Environmental, Economic, and Socio-cultural) and 12 sub-criteria (Collection method, Collection frequency, Regulatory norms, air quality, energy saving, Environmental awareness, capital cost, operation cost maintenance cost, participation of public, planning, monitoring \& control of operations and public health and hygiene) and 4 alternatives (Door to Door collection of waste using wheelbarrow (CT-1), Door to Door collection using rickshaw and tri-cycle (CT-2), collection by compact truck (CT-3) (from collection point to landfill) and collection by trucks and tippers (CT-4) (from households). Fig. 1 shows the hierarchical structure developed for selecting the best alternative of solid waste collection and transportation.

\section{Establishing the Pairwise Comparison Matrix for Criteria and Sub-Criteria}

The comparative importance of criteria are evaluated by six experts and the scores were totaled by the geometric mean method. The criteria weights are computed using the Additive Normalization Method as described in section 4. The pairwise comparison matrix of criteria and sub-criteria are presented in Table 2 and Table 3 respectively. Table 4 shows

Table 1: RI values based on matrix size.

\begin{tabular}{|llllllllllll}
\hline $\mathrm{n}$ & 1 & 2 & 3 & 4 & 5 & 6 & 7 & 8 & 9 & 10 \\
\hline $\mathrm{RI}$ & 0 & 0 & 0.58 & 0.9 & 1.12 & 1.24 & 1.32 & 1.41 & 1.45 & 1.49 \\
\hline
\end{tabular}

Table 2: Pair-wise comparison matrix of criteria.

\begin{tabular}{|llllll|}
\hline Criteria & Technical & Environmental & Economical & Socio-cultural & Weights \\
\hline Technical & 1 & 5 & 5 & 5 & 0.4942 \\
Environmental & 0.2 & 1 & 5 & 5 & 0.2822 \\
Economical & 0.2 & 0.2 & 1 & 5 & 0.1515 \\
Socio-cultural & 0.2 & 0.2 & 0.2 & 1 & 0.072 \\
\hline
\end{tabular}

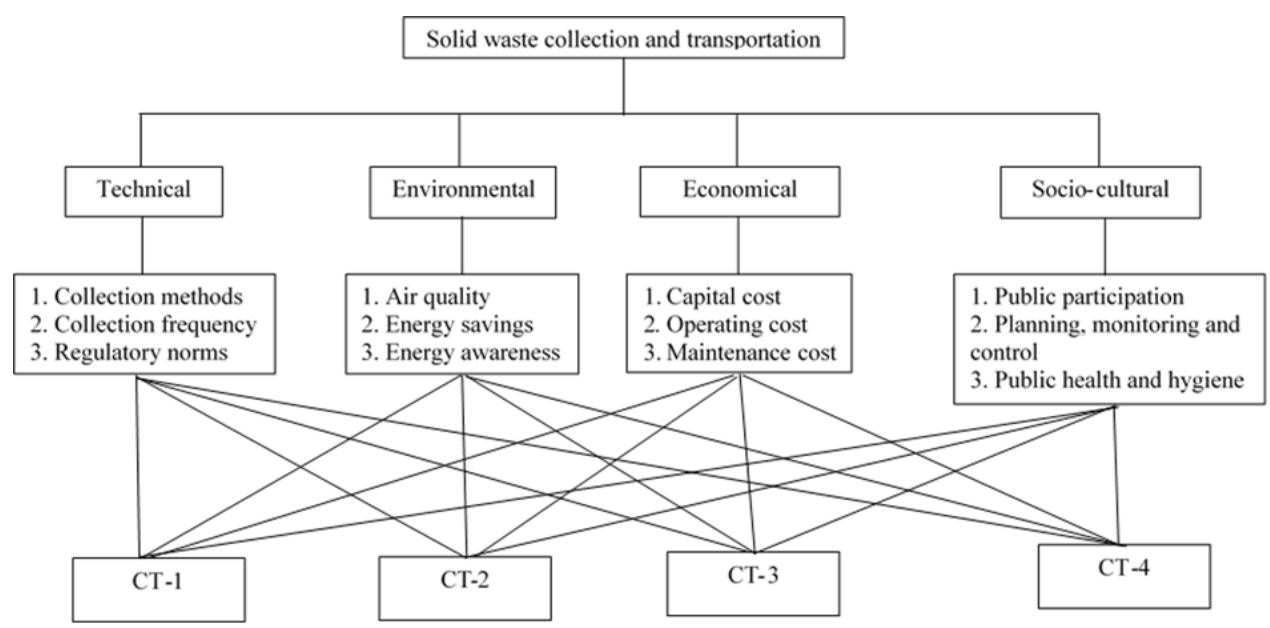

Fig. 1: Hierarchical structure for selecting the best alternative of solid waste collection and transportation. 
Table 3: Pair-wise comparison matrix of sub-criteria (relating to technical).

\begin{tabular}{|lllll|}
\hline Sub-criteria & Collection method & Collection frequency & Regulation & Weights \\
\hline Collection method & 1 & 7 & 5 & 0.6845 \\
Collection frequency & 0.142 & 1 & 5 & 0.2274 \\
Regulation & 0.2 & 0.2 & 1 & 0.0879 \\
\hline
\end{tabular}

Table 4: Pair-wise comparison matrix of alternatives relating to collection method.

\begin{tabular}{|llllll|}
\hline Alternatives & CT-1 & CT-2 & CT-3 & CT-4 & Weights \\
\hline CT-1 & 1 & 0.33 & 0.1428 & 0.2 & 0.0567 \\
CT-2 & 3 & 1 & 0.2 & 0.33 & 0.1218 \\
CT-3 & 7 & 5 & 1 & 3 & 0.5579 \\
CT-4 & 5 & 3 & 0.33 & 1 & 0.2633 \\
\hline
\end{tabular}

the pair-wise comparison matrix of alternatives in regard to the collection method.

\section{Computing the Final Weight of Each Sub-Criterion}

The final weight of each sub-criterion is calculated and depicted in Table 5 .

\section{Arriving AHP Performance Scores and Ranking for each Alternative}

The scores are computed by adding the product weight of the alternatives with the corresponding sub-criteria weight. The final scores of alternatives are computed and depicted in Table 6.

From Table 6, it is found that final AHP score is $29.21 \%$, $18.92 \%, 33.89 \%$ and $17.89 \%$ for alternative $1,2,3$ and 4 respectively. Since alternative 3 has the highest score (33.89\%) than other options, it will be ranked as the best choice while considering all criteria and sub-criteria. To simplify the calculations involved in the proposed model, a decision support system was developed using EXCEL. This DSS will help the decision-makers to get the solutions quickly and accurately.

\section{CONCLUSION}

Due to population growth, industrialization, and urbanization solid waste management has become a significant issue worldwide. Unproductive waste collection methods have an impact on the public health and aesthetics of towns and cities. In this study, the existing practice of solid waste collection and transportation methods adopted in GVMC is explained. It is found that waste collection and transportation is the major problem in implementing effective SWM. To evaluate the collection and transportation of solid wastes, an

Table 5: Computation of final weight of sub-criteria.

\begin{tabular}{|c|c|c|c|c|}
\hline Criteria & Weight of criteria & Sub-criteria & Weight of Sub-criteria & Total of weight of Sub-criteria \\
\hline \multirow[t]{3}{*}{ Technical } & 0.4942 & Collection method & 0.6845 & 0.3382 \\
\hline & & Collection frequency & 0.2274 & 0.1124 \\
\hline & & Regulation & 0.0879 & 0.0434 \\
\hline \multirow[t]{3}{*}{ Environmental } & 0.2822 & Air quality & 0.6582 & 0.1857 \\
\hline & & Energy saving & 0.2806 & 0.0792 \\
\hline & & Energy awareness & 0.061 & 0.0172 \\
\hline \multirow[t]{3}{*}{ Economical } & 0.1515 & Capital cost & 0.663 & 0.1004 \\
\hline & & Operating cost & 0.2558 & 0.0388 \\
\hline & & Maintenance cost & 0.0811 & 0.0122 \\
\hline \multirow[t]{3}{*}{ Socio-cultural } & 0.072 & Participation of public & 0.7288 & 0.0524 \\
\hline & & Planning, monitoring, and control & 0.2161 & 0.0155 \\
\hline & & Public health and hygiene & 0.0549 & 0.0039 \\
\hline
\end{tabular}


Table 6: Computation of final scores of alternatives.

\begin{tabular}{|lllll|}
\hline Sub-criteria & CT- 1 & CT-2 & CT-3 & $0.338 * 0.558$ \\
\hline Collection method & $0.338 * 0.056$ & $0.338 * 0.122$ & $0.338 * 0.263$ \\
Collection frequency & $0.112 * 0.623$ & $0.112 * 0.216$ & $0.112 * 0.105$ & $0.112 * 0.054$ \\
Regulation & $0.043 * 0.05$ & $0.043 * 0.283$ & $0.043 * 0.345$ & $0.043 * 0.32$ \\
Air quality & $0.186 * 0.548$ & $0.186 * 0.255$ & $0.186 * 0.144$ & $0.186 * 0.051$ \\
Energy saving & $0.079 * 0.574$ & $0.079 * 0.276$ & $0.079 * 0.114$ & $0.079 * 0.035$ \\
Energy awareness & $0.017 * 0.596$ & $0.017 * 0.241$ & $0.017 * 0.124$ & $0.017 * 0.07$ \\
Capital cost & $0.100 * 0.042$ & $0.100 * 0.114$ & $0.100 * 0.49$ & $0.100 * 0.343$ \\
Operating cost & $0.038 * 0.049$ & $0.038 * 0.098$ & $0.038 * 0.515$ & $0.038 * 0.336$ \\
Maintenance cost & $0.012 * 0.042$ & $0.012 * 0.141$ & $0.012 * 0.473$ & $0.012 * 0.342$ \\
Participation of public & $0.052 * 0.505$ & $0.052 * 0.325$ & $0.052 * 0.109$ & $0.052 * 0.06$ \\
Planning, monitoring and control & $0.015 * 0.613$ & $0.015 * 0.208$ & $0.015 * 0.128$ & $0.015 * 0.05$ \\
Public health and hygiene & $0.004 * 0.158$ & $0.004 * 0.190$ & $0.004 * 0.45$ & $0.004 * 0.20$ \\
Total weight & 0.2921 & 0.1892 & 0.3389 & 0.1789 \\
\hline
\end{tabular}

Analytic hierarchy process is applied and it is found to be an effective tool for evaluating the suitable collection and transportation alternatives in GVMC.

The decision hierarchy for this problem is constructed by considering 4 criteria, 12 sub-criteria, and four alternative methods of collection and transportation. Out of the 4 criteria identified, technical factors of collection and transportation is considered to be more important as it has more weight than the other three. It is evident that alternative 3, collection by compact truck is having the highest overall AHP score $(33.90 \%)$ than the other three alternatives. By considering all criteria and sub-criteria, it can be found that alternative 3 is ranked as the best alternative for solid waste collection and transportation in GVMC.

The benefits of the proposed AHP model are listed below:

(i) Scores of the criteria are computed to show the comparative significance of all criteria and sub-criteria.

(ii) The consistency of pairwise comparisons is checked through the consistency ratio

(iii) The alternative selection by AHP matches with the actual scenario

\section{Limitations of the Proposed Model}

The proposed model is based on the existing practices of GVMC for evaluating the suitable collection and transportation alternatives of solid waste using AHP. The criteria and alternatives chosen in this model are restricted to the case study conditions.

Other MCDM methods, combined with various ranking methodologies, should be considered for enhancing the solid waste collection and transportation evaluation process. Other parameters that will have an impact on the selection problem should be included in addition to the criteria presented in this case study. The research can be expanded to include other SWM applications, such as determining the best landfill location and SWM equipment.

\section{ACKNOWLEDGEMENT}

The authors are grateful to their management for allowing them to do this research and thankful to the anonymous referees for their valuable suggestions to enhance the features of the content.

\section{REFERENCES}

Achillas, C.H., Vlachokostas, C.H., Moussiopoulos, N. and Banias, G. 2010. Decision support system for the optimal location of electrical and electronic waste treatment plants: A case study in Greece. Waste Management, 30 (5): 870-879.

Chouhan B.M and Reddy B.K. 1996. Bio-energy scenario in India.IREDA News. 7(1): 20-27.

Goulart Coelho, L.M., Lange, L.C. and Coelho, H.M. 2017. Multi-criteria decision making to support waste management: A critical review of current practices and methods. Waste Manag. Res., 35(1): 3-28.

Greater Visakhapatnam Municipal Corporation, www.gvmc.gov.in.

Hazra, T., Maitra, B. and Goel, S. 2017. Development and application of a multi-criteria decision making (MCDM) tool for solid waste management: Kolkata as a case study. Adv. Solid Hazard. Waste Manag., 3: 275-300 https://doi.org/10.1007/978-3-319-57076-1 14.

Jovanovic, S., Savic, S., Jovicic N, Boskovic, G. and Djordjevic, Z. 2016. Using multi-criteria decision making for selection of the optimal strategy for municipal solid waste management. Waste Manag. Res., 34(9): 884-895.

Kameswar Rao, S. 2019. Municipal solid waste management in Visakhapatnam city, India. Int. J. Eng. Adv. Technol., 8(6): 3604-3607. 
Lee, W.B., Lau, H., Liu, Z.Z. and Tam, S. 2001. Fuzzy analytic hierarchy process approach in modular product design. Expert Sys., 18: 32-42.

Mazumdar, N.B. 1994. Municipal solid waste management the Indian perspectives, Environment Monitor, 12(2): 257-269.

Moeinaddini, M., Lee Khorasani, N., Danehkar, A., Darvishsefat, A.A. and Zienalyan, M. 2010. Siting MSW landfill using weighted linear combination and analytical hierarchy process (AHP) methodology in GIS environment (case study: Karaj). Waste Management, 30(5): 912-920.

Saaty, T.L. 1980. The Analytic Hierarchy Process. McGraw-Hill, New York (NY).

Saaty, T.L. 2000. Fundamentals of Decision Making and Priority Theory with AHP. RWS Publications, Pitsburg.

Sekhar, S. and Bidarkar, S. 1999. Municipal budgets in India: Comparison across five cities. Econ. Pol. Weekly, 34(20): 1202-1208.
Torkayesh, A.E., Malmir, B. and Rajabi Asadabadi, M. 2021. Sustainable waste disposal technology selection: The stratified best-worst multi-criteria decision-making method. Waste Manag., 122 (2): 100-112.

Ulukan, H.Z. and Kop, Y. 2009. Multi-criteria decision making (MCDM) of solid waste collection methods using Life Cycle Assessment (LCA) outputs. International Conference on Computers \& Industrial Engineering, 6-9 July 2009, University of Technology of Troyes, France, Piscataway, NJ IEEE, pp. 584-589. doi: 10.1109/ ICCIE.2009.5223862.

Yildirim, V., Memisoglu, T., Bediroglu, S. and Colak, H. E. 2018. Municipal solid waste landfill site selection using Multi-Criteria Decision Making and GIS: A case study of Bursa province. J. Environ. Eng. Landscape Manag., 26(2): 107-119. 